\title{
A BILL OF RIGHTS FOR NORTHERN IRELAND - LANGUAGE ISSUES IN CONTEXT
}

\author{
Caoimhghin Ó Murchadha, An Gaeláras, Derry and Lee Reynolds, \\ Ulster Scots Heritage Council

\section{INTRODUCTION}

This paper will compare the Northern Ireland Human Rights Commission's (NIHRC) recommendations contained in the language section of "Making a Bill of Rights for Northern Ireland" with the report ${ }^{1}$ produced by the Language Rights Working Group (LRWG) and Cultural Identity Working Group (CIWG).

It will explain about the operation of the LRWG and the broad approach that was taken by the authors ${ }^{2}$ of the report. Section one by Lee Reynolds will look at the NIHRC cultural and language recommendations and compare them with international standards and the LRWG's work. Section two by Caoimhghin O'Murchadha will look at the context of the NIHRC's work.

\section{(a) The Language Working Group}

The manner of appointment to the LRWG was different from the other working groups. The NIHRC approached a number of organisations asking them to nominate members. The different language communities had different levels of representation - four for Irish, two for Ulster-Scots, two for Chinese, one each for the Indians, Muslims, Travellers, blind and deaf. Patrick Yu of NICEM (Northern Ireland Council for Ethnic Minorities) was appointed as chair and Paddy Kelly as the Commissioner with responsibility for the group. To inform its deliberations the LRWG ran a one-day conference and each member was invited to make a submission.

There were a number of issues that hampered the work of the LRWG. First, there was confusion about the status of group members. The NIHRC view was that they were individuals with skills there to provide independent advice. LRWG members viewed themselves as representatives of the organisations that had been asked to nominate them. This was never resolved. Second, there were persistent problems with the thoroughness of the minutes provided by the NIHRC. Third, Patrick Yu had much to offer the debate and work of the committee but this interfered with his role as chair. Fourth, just as the issues of identity, language and culture are contentious in our society so were many of the debates in the LRWG.

1 The Language Rights Working Group and Cultural Identity Working Group reports can be downloaded from www.nihrc.org in the Bill of Rights section, subsection working group reports.

2 Caoimhghin O’Murchadha and Lee Reynolds 


\section{(b) The Approach to the Working Group Report}

The responsibility of drawing all the work into a final report was given to two LRWG members. The authors adopted a three-fold approach to the drafting of the report. First, that it would follow best international practice. Second, that it would treat the different language communities in an equal manner. Third, that the report should be viewed realistically by the various language communities. A Bill of Rights was not going to be a panacea for language communities. The work and commitment to maintain and develop the language communities would have to continue whatever a Bill of Rights did or did not say.

This approach obviously worked as the working group adopted the final report with one dissension (largely because the proposals did not go far enough). A consensus the NIHRC has chosen to ignore.

\section{NIHRC CULTURAL AND LANGUAGE RECOMMENDATIONS}

\section{(a) What the Cultural Identity Working Group Recommended}

The Cultural Identity Working Group had the task of squaring the circle between parity of esteem for the two communities and equality for all. The cultural working group, influenced by the advice of OSCE, recommended:

- $\quad$ Equality for all communities

- The adoption of the provisions of the Framework Convention for National Minorities

- The use of the term community instead of minority

These have been included in the recommendations of the NIHRC. They believe the parity of esteem issue is addressed by including it in the preamble and that ". . . the entire range of rights recommended for the Bill of Rights as providing a basis for parity of esteem among all communities in Northern Ireland". However, there seems to be a lack of consensus on the parity of esteem issue in the Commission and it does offer the option of a direct clause.

\section{(b) Parity Of Esteem}

The problem with debating the issue of parity of esteem is that it very quickly descends into a Unionist v Nationalist argument. Most Unionists consider "parity of esteem" as nationalist terminology. They claim it is either meaningless rhetoric or impossible to define. Nationalists place strong emphasis upon the "parity of esteem" terminology and argue that definition is possible. They say Unionists just do not like the consequences that must flow from Unionism's acceptance of the term in the Agreement. Unionists counter that the acceptance by Nationalists of Northern Ireland's constitutional status overrides any implications of parity of esteem. And so on and so on.

\section{(c) Cultural Communities?}

However there is one recommendation that is missing which has significant implications for the Ulster-Scots community and this concerns the issue of 
culture. There are four categories of communities protected in the cultural section - national, ethnic, religious and linguistic. The CIWG recommended that cultural be included in the categories of communities. NIHRC has not included it. This omission results in limited protection for the Ulster-Scots community.

The Government does not recognise Ulster-Scots as a national community; the Equality Commission does not accept Ulster-Scots as an ethnic group; the Ulster-Scots community is not religiously homogenous and the linguistic section of the Ulster-Scots community is smaller than the cultural community.

\section{(d) Dangerous Flaws?}

In terms of provision for all communities the draft bill has three weaknesses. First, a community, especially a minority one, needs access to the education system, the cultural institutions and the media in order to survive and hopefully thrive in the modern world. Moreover, the international standards acknowledge this need. In an attempt for international standards to avoid "ghettoisation" of a community/minority, additional provisions for mutual respect, understanding and co-operation are made. In clause 5(c) of the NIHRC draft access to the above is strictly placed in a cultural diversity context. This raises the question whether a community will only get access if all other communities are directly involved too?

Secondly, although the UN's Convention on the Rights of the Child and the European Charter for Regional and Minority Languages make clear references to the need for a child to be educated in his/her own language or culture, there is nothing or little proposed in the Children's rights section or the Educational rights section of the draft bill. Thirdly, there is no clear protection against assimilation as provided in the Framework Convention on National Minorities.

In conclusion, it must be stated that most of the recommendations of the identity working group have been adopted by the NIHRC in its draft, however that which has been omitted has the potential to be of serious consequence.

\section{(e) What the Language Group Recommended}

The Language Working Group report defined what languages were to be included with flexibility around the languages of minority ethnic communities. It set out the duties of the state to provide for positive policies and provision in the public sector and media access. These duties were strong but were couched with up to five qualifiers that the state could take into account: usage, need, demand, practicality and the situation of each language. In the area of judicial rights it recommended the right to use the language within the judicial system and also agreed that documents in languages other than English would be admissible within the judicial system and be invokable.

The education rights allowed for the establishment of independent schools, the state provision of educational materials at all stages of education, cultural education, educational opportunities for non-speakers, support for valuable research and assistance in the learning of English. Furthermore, a member of 
a linguistic community could communicate with public bodies in their own language. Under media rights it recommended that a linguistic community could establish their own media institutions, they could receive media from abroad and that public broadcasters had to take their views into account (all within the normal regulatory framework).

\section{(f) The NIHRC Recommendations}

There is a substantial difference in what the working group outlined and what the NIHRC recommended. The first clause of the NIHRC recommendations grants the right to use a language for private purposes and extends recognition beyond language speakers to dialect speakers. The second is the right to translation services to access essential services. The third is the right to assistance to learn English. The fourth calls for legislation for Ulster-Scots and Irish based on Charter recognition. The fifth provides six basic rights - development of the language, use with public bodies, use and recognition of names, the public display of signs, local street and place names and to learn it - with the qualifier of sufficient demand. No definition of sufficient demand is given other than it includes availability of resources.

These proposals are very conservative. What is worse is that they do not meet basic international standards. Also, despite the recognition in the cultural rights section of equality for all, a strong distinction is drawn in the language section between the indigenous and non-indigenous languages and potentially between Irish and Ulster-Scots.

Minority language speakers have the right to speak their language in public and not solely in private. A minority language community is entitled to certain basic rights. It is entitled to further rights on the basis of qualifiers such as demand. This approach is best reflected in the European Charter. However, the NIHRC makes a substantial element of the rights subject to the qualifier of demand. What has demand got to do with recognition for someone's name in their own language? Also the NIHRC does not define what sufficient demand means other than the fact that it includes availability of resources. Thus, government saying it has no money will stop real progress and judges will be dragged into adjudicating resource allocation issues.

\section{(g) Ulster-Scots Concerns}

The Ulster-Scots community has a number of deep concerns. This is a carefully crafted document however there is not one solitary reference to Ulster Scots as a language. This is viewed by Ulster-Scots as a clear and premeditated slight on Ulster-Scots. The inclusion of dialect speakers, never heard before, leads many to believe that is there is a reference to UlsterScots. The minority ethnic groups certainly never raised it in the working group. Secondly, Ulster-Scots are much more wary of the idea of legislation. Legislation will take a long time; it will turn the issue into a political football; it will institutionalise inequality between Ulster-Scots and Irish. Ulster-Scots has Part 2 recognition under the European Charter for Regional and Minority Langauges. Irish has Part 3 recognition under the Charter. Legislation as suggested by the NIHRC would institutionalise this differential. Thirdly, in the education section only the Irish language 
medium sector is recognised. There is no scope in the NIHRC's proposals for an Ulster-Scots medium sector or minority ethnic language sectors to develop.

\section{THE CONTEXT OF THE NIHRC'S WORK}

As a nominee from An Gaeláras, Doire, to the Northern Ireland Human Rights Commission's working group on language I welcomed my appointment as giving me an opportunity to make an input at another level into a process that directly affects the work that myself and my colleagues are engaged in daily - that of establishing rights and creating an environment where such rights are protected and wherein the many projects that we are engaged in can flourish.

As a representative from an Irish language organisation I understood fully what it meant to have few or no rights, and how opposition to the assertion of rights could lead to conflict and contention. Coming from a constituency that had survived a distinctly hostile cultural climate our perception of the work of the Northern Ireland Human Rights Commission was that it marked the emergence of official recognition of the need for a process that would establish a template for a society that was based upon genuine principles of equality and a healthy respect for cultural diversity.

Attendance at the working group was a part of that process, and the brief that I took from my organisation was not that of "fighting our corner" but of striving to create a cultural context that would be of benefit to all. There is a saying in Irish "Ceart dom, ceart duit" - "I have rights, you have rights" and that was the spirit and mindset that informed my approach to the working group. Of course Irish speakers have a "shopping list", as do other groups and organisations, but we never felt that the NIHRC was likely to publish a report that would enable us to pack up our tents and retire and working group duties were undertaken in the full knowledge that whatever the NIHRC produced the lobbying and development would have to continue.

We had hopes of course, and still have them. The NIHRC is itself a child of the Good Friday Agreement, a part of the peace process that we all have a stake in, whether we are supporters of the Good Friday Agreement or not. Notwithstanding our positions with regard to that agreement, if we are genuine about establishing a polity that cherishes all its citizens equally then it follows that the challenge of creating a healthy society following years of bitter conflict requires a very careful assessment of the seeds of that conflict and their removal.

Viewed thus, language issues are not some trivial addition to more weighty affairs but are inextricably linked to the conflict and its resolution. Questions of identity, of the right to fully embrace all aspects of one's culture and to be afforded equality under the law are crucial ones. In addition to respecting and underpinning the rights to express and develop certain cultural manifestations of British, Irish or Ulster Scots identity, the reality that there are others who have linguistic and cultural needs and rights, including some more recent arrivals to these shores, is one that also has to be recognised and addressed. And as the work of the working group progressed and its members looked beyond ethnic labels it was recognised that there were others too, who, by reason of illness or disability, had special communication 
needs that often effectively led to their exclusion from the existing rights and opportunities that most people enjoyed.

As meeting followed meeting, as "shopping lists" gave way to a deeper respect and understanding of the needs and aspirations of others, the group moved closer to a consensus about the way forward. We had a sense that here was an opportunity to shape a society that truly respected all its citizens. We looked at issues and solutions in other jurisdictions; we looked at European and international standards; we pored over the language clauses in the Good Friday Agreement. We had, and I believe eventually took, a chance to emulate anything that these documents offered in terms of concrete and enforceable rights, a chance to craft a genuinely inclusive document that would reflect a multicultural society at ease with itself. If all the various nominees on the working group are viewed as representative of the pieces of the mosaic that make up our society there existed an opportunity to ensure that no one was excluded from the final picture that emerged of the group's view of a fairer world.

It was put to us that following our draft report the NIHRC would draw up a consultation document and that later the Secretary of State would have the final say in what went into the Bill of Rights. I remember feeling a frisson of annoyance that any one individual could put a pen through the hard won consensus of representatives of the many, representatives who had considerable expertise and who had sought to put individual politics aside in the search for common ground and mutual respect. Ours was not an extremist draft, it was inclusive, it was reasonable and it had earned the support of almost every member of the working group.

I recalled the words of the Irish author Breandán Ó hEithir, who, writing in The Irish Times of $7^{\text {th }}$ April 1977 on the problems of writing in Irish had this to say,

“... The language movement I hope to deal with at length in a future article in this paper so, for the moment, the following brief comment will suffice. The movement, such as it is, is not led by fanatics or hard headed thinkers, as is fondly imagined by some. The vast majority of them are gullible poor hoors who sit on committees which draft plans which are never implemented by the shifty-eyed civil servants who castrate them on the instructions of their political masters."

That was another time, another place and, for legal purposes, another State. We've all seen too many episodes of "Yes Minister" to imagine that such sharp practice could be applied to the constituent parts of a delicate peace process - haven't we?

Perhaps not, was my first reaction upon viewing the NIHRC consultation document. I felt cheated, almost abused, and was left with a strong feeling that my time and that of my colleagues on the working group had been wasted. Gone were the brave new world, the fresh start, and the respectful template. In its place was an anodyne document, vague in its language and frequently no more than a restatement of existing rights. References back to the Good Friday Agreement were, I believe, a failure of nerve, as that document too had its fair share of vagueness. Elements contained in the Good Friday Agreement were tinkered with, rights affecting the disabled 
were dropped, and the consensus of the working group seemed to have been overturned by a lack of consensus among the Commissioners.

The NIHRC consultation document, gutted of the carefully considered detail contained in our draft, represents a lost opportunity to depoliticise language issues and leaves progress hostage to dispute and litigation. This may be a lawyer's dream but for a society attempting to emerge from conflict the document has more of a nightmarish tinge.

The management of change requires courage, not caution and the NIHRC has many nettles to grasp. The consultation document is not the final word it is but a part of a process, and in it the NIHRC has seriously mishandled the language question. Perhaps the deadlines set for the document's publication were unhelpful, perhaps the Commission should have met the working group subsequent to the production of the group's draft and discussed it more fully. Whatever the case, one does not abandon one's friends because they make mistakes; one encourages them to learn and to improve on them. The next part of the process should be a reengagement between the NIHRC and the working group and a return to our hard won consensus - we deserve nothing less. 